\title{
Off-label use of medicinal products in oncology: exercising due diligence or experimental activity?
}

\author{
Justyna Estera Król-Całkowska', Janusz Jaroszyński²
}

\author{
'Department of European and International Law, Faculty of Law and Administration, Lazarski University, Warsaw, Poland \\ ${ }^{2}$ Department of Administrative Procedure, Faculty of Law and Administration, Maria Curie-Sklodowska University of Lublin, Lublin, Poland
}

\begin{abstract}
One of the primary responsibilities of a physician is to diagnose and treat diseases with due diligence. Exercising due diligence in treatment process involves, among others, the use of optimal diagnostic, therapeutic and follow-up management in accordance with the current state of medical knowledge. Each medicinal product has the Summary of Product Characteristics which defines, among others, registered indications, the age group for which the product is registered, the dosing scheme, and route of administration of the product. Polish law does not refer directly to the admissibility of products that use off-label nor does it include regulations forbidding such activities. Considering a number of problems associated with products which use off-label and, on the other hand, commonness of such activities, it is necessary to introduce legal regulations defining the legitimacy and admissibility of such methods of proceeding.
\end{abstract}

Key words: off-label use, oncology treatment, medical experiment, due diligence, reimbursement of drugs

\section{Introduction}

According to article 4 of the Act on the Profession of Doctor and Dentist [1], one of the fundamental responsibilities of a physician is to diagnose and treat diseases with due diligence. Within due diligence, a physician is obliged to apply available methods and means of preventing, diagnosing, and treating diseases, including especially, those being optimal procedures in time offering the best chances of treatment success. Often it requires the use of medicinal products discordant with the provisions of the Summary of the Product Characteristics (SPC), for instance, due to the lack of medicinal products registered in a particular indication or in a specified age group. Exercising due diligence in the treatment process involves, among others, applying optimal diagnostic, therapeutic, and follow-up management in line with the current state of medical knowledge. The authors state that current medical knowledge should be understood as reflecting recent guidelines, management schemes, and treatment standards formulated by scientific societies and groups of experts, as well as applying the elements of evidence based medicine (EBM) as a supplementary factor.

The issue of due diligence is directly referred to article 355 of the Civil Code [41] stating that"the debtor is obliged to perform generally required diligence in relationships of a particular type (due diligence)". In the physician-patient relationship, a physician becomes the stipulated debtor and, at the same time, guarantor of the patient's life and health which binds a physician to undertake any actions focused on the intended objective. The ground for these actions is undoubtedly due diligence understood as treatment implementation based on the current medical knowledge supplemented with EBM. The element of due diligence is, among others, the implementation of pharmacological therapy with the use of medicinal products

\section{How to cite:}

Król-Całkowska JE, Jaroszyński J. Off-label use of medicinal products in oncology: exercising due diligence or experimental activity? NOWOTWORY J Oncol 2022; 72: 26-33.

This article is available in open access under Creative Common Attribution-Non-Commercial-No Derivatives 4.0 International (CC BY-NC-ND 4.0) license, allowing to download articles and share them with others as long as they credit the authors and the publisher, but without permission to change them in any way or use them commercially. 
in an optimized manner and adjusted to the individual needs of the patient. According to article 2 item 32 of the Pharmaceutical Law Act [2], a "medicinal product" should be understood "as a substance or a combination of substances presented as owning properties to prevent or treat diseases in humans or animals or administered to diagnose or restore, improve or modify the physiological functions of an organism through pharmacological, immunological or metabolic activities".

Each medicinal product has the Summary of Product Characteristics (SPC) which determines, among others, registered indications, the age group for which the product was registered, dosage regimen, and route of administration of the product. In clinical practice medicinal products are also used beyond SPC provisions (off-label use) which is a result of, among others, constantly developing medical knowledge, a patient's individual needs and strictly formal reasons - i.e. the lack of verification of SPC content which was established several or a dozen or so years earlier. Off-label use of medicinal products implies a number of questions of a legal nature, including the admissibility and legal compliance of such activity, and the responsibility of health care professionals regarding negative effects arising from initiation or continuation of off-label treatment.

\section{Aim}

The aim of this paper is to analyze the admissibility of off-label use of medicinal products in oncology and to indicate whether such activity should be identified as exercising due diligence or rather as an experimental activity. The subsidiary aim is to indicate a physician's responsibility to provide information on treatment implemented off-label before its commencement. The paper deliberately omits principles of responsibility associated with the use of medicinal products discordant with the provisions of the Summary of Product Characteristics. Given the extensiveness of the subject associated with physician responsibility due to off-label use of drugs, a separate paper should be dedicated to this issue.

\section{Material and methods}

This paper uses analysis of the provisions of the law, the present position of the doctrine, and jurisprudence. The material involves current legal regulations referring to conducting therapeutic experiments, principles of using medicinal products as well as principles of expressing consent to treatment. The fundamental material was complemented by the positions grounded in the doctrine and content of the current Polish Courts' Case Law on the use of medicinal products beyond SPC provisions.

\section{Admissibility of off-label use of medicinal products in oncology}

In many fields of medicine, off-label use of medicinal products constitutes a typical and completely acceptable activity in light of current medical knowledge. According to the WHO, half of all drugs available on the worldwide pharmaceutical market is at least incidentally used in a manner not stated in the instructions [3]. In 1997, the FDA defined this method of therapy as "off-label use" referring to the use of drugs in unregistered indications, in a dosage or scheme varying from SPC provisions, or in a population for which the drug was not registered [4].

The Summary of Product Characteristics is created based on the European Parliament and Council Directive 2001/83/WE on community code referring to medicinal products used in humans [5] and the Pharmaceutical Law Act [2]. The information included in SPC is the result of clinical trials conducted for registration of a particular drug. Article 11 section 1 items 1-13 of the Pharmaceutical Law Act [2], includes a list of information necessary to include in the content of the summary of product characteristics. The most important include: clinical data involving indications for use, dosage and route of administration, contraindications, special warnings and precautions for use, interactions with other medicinal products or other forms of interactions, use during pregnancy and breast-feeding, effects on the ability to drive and use machinery, adverse reactions, overdose and antidotes, pharmacological properties, pharmaceutical data on, among others, expiry date, special precautions for storage, name and address of marketing authorization holder. The listing of all SPCs for drugs authorized for use is available on the website of the Office for Registration of Medicinal Products, Medical Devices and Biocidal Products (URPL) [6].

The literature indicates the following off-label drug use amounts: $7.5-15 \%$ in typical outpatient internal indication, $30-50 \%$ in oncology patients and even $90 \%$ in the case of neonatology and pediatric oncology. Off-label use is especially common in the field of pediatrics, oncology, dermatology, hematology, and palliative care [7]. Review of the literature concerning off-label use of drugs in oncology indicates that it is common practice used with various intensity by oncologists around the world.

The authors M.M. Saiyed, P.S. Ong, and L. Chew indicate that the use of drugs beyond registration indications in hospitalized oncology patients varied between 18\% and 41\% [8]. Among adult patients with cancer, $13-71 \%$ received at least one off-label chemotherapy. Major reasons for off-label drug use was the lack of product registration in the treatment of diseases diagnosed in a patient, or the necessity to retreat from the dosage scheme indicated in the SPC [8]. The scale of needs for off-label treatment in oncology is depicted by research conducted by A.K. Herbrand, A.M. Schmitt, M. Briel, et al. in years 2015-2018. Research conducted in a Swiss population demonstrated that $45 \%$ of first line treatment cases in a group of 3046 patients treated for cancer was associated with a decision to implement off-label treatment [9]. In a study published in 2021, Japanese researchers demonstrated that diseases most commonly treated off-label were sarcoma, urologic cancers, and gastrointestinal cancers [10]. Research conducted in Peter 
MacCallum Cancer Centre in Australia demonstrated that prescribing beyond registered indications is prevalent in patients hospitalized due to acute cancer wherein approximately $22 \%$ of all prescriptions concern off-label or unlicensed drugs [11]. Off-label use in oncological treatment is also prevalent in Germany [12] and France [13].

It should be emphasized that, beside oncology, off-label therapy is prevalent in the pediatric and neonatology population. Research conducted in Europe indicates that at least one third of hospitalized children and up to $90 \%$ of infants treated in neonatal intensive care units are administered off-label treatment [14].

Polish literature [15] distinguishes four cases of the use of drugs beyond strictly registered indications, involving the use of:

- a medicinal product in a manner or with the route of administration which was not stated in the Summary of Product Characteristics,

- a drug in line with registered indication in patients for whom dosage was not determined,

- a drug in an indication which was not listed in the Summary of Product Characteristics but for which reliable data confirming its safety and efficacy exist,

- a drug in a new indication which is not yet supported by evidence, but for which there are scientific foundations allowing to expect its efficacy and safety.

In the opinion of I. Vrancken, the notion of off-label use should be primarily understood as the use of drugs in the population which was not stated in the SPC as well as discordant with the registered indication [16]. The literature also items out that the use of drugs beyond SPC may stand for the use of a drug in a different age group, other doses or discordant with the purpose [17]. In the opinion of the authors, off-label use of medicinal products should be divided into two categories:

- off-label use of medicinal products in the primary meaning - i.e. the use of products discordant with the registered indications (beyond registered indications), or in an age group for which the drug was not registered,

- off-label use of medicinal products in the secondary meaning - i.e. the use of products in different dosing schemes or route of administration as well as the modification of other SPC provisions.

The literature referring to the legal aspects of the use of medicinal products beyond SPC defines off-label use also as the use of a product discordant with the approved product information, as well as the implementation of treatment in a different manner than that stated in the patient information leaflet (PIL) [18].

Regarding the meaning of the Summary of Product Characteristics, the Court of Appeal in Warsaw in its judgement of 14.02.2014 [19] emphasized that "SPC is one of the crucial documents in marketing authorization procedure for medical products, it contains data of a manufacturer, composition, ac- tion, posology and any identified risks associated with the use of a particular product, however it is not of a normative nature, but rather informative one concluding the state of knowledge on this product in a particular moment. Considering continuous development in medical knowledge, a physician must have appropriate license to adjust the use of drugs to current achievements of medicine and the needs of a particular patient".

On the other hand, the Supreme Court in the judgement of 24.11.2011 [20] referred to the relationship of SPC provisions to a physician's decision on drug dosage. The Supreme Court stated that: "a physician's entitlement to prescribe a dosage regimen recognized as appropriate, arises from the fact that he makes therapeutic decisions and is responsible for them, therefore, in any event, he cannot be bound by a dosing regimen determined in the summary of product characteristics. A physician's decision on dosage regimen must consider the individual needs determined by the health state of a particular patient and other professionally assessed circumstances; if it was to be otherwise $\S 8$ section 1 item 2 of the Regulation of the Minister of Health of 17.05.2007 would be completely redundant or would lead to the absurd conclusion that a physician is obliged to automatically duplicate only the dosage regimen determined in the summary of product characteristics".

A similar statement was issued by the Supreme Court in the resolution of 26.10 .2011 [21], emphasizing that "article 45 of the Act on the Profession of Doctor and Dentist of 5.12.1996 (...) and article 10 section 1 item 11 and article 11 section 1 item 4 of the Pharmaceutical Law Act of 6.09.2001, do not lay the foundation to assume that a physician is bound by the dosage regimen included in the summary of the product characteristics".

The presented jurisprudence indicates that SPC provisions are only of a formal nature and in each case do not guarantee proceeding in line with the current medical knowledge. The doctrine mentions that the medical knowledge resulting from research must be publicly released in a verifiable form, so as to allow not only control and possible criticism of the accuracy of the applied method, but also the replication of research in line with the proposed method in order to compare the obtained results [22].

At the same time, the literature emphasizes that "no regulation requires that, for valid and efficient execution of a physician's competence to prescribe a drug (in any form), a medical product is prescribed in line with registered indications" and "there are no detailed rules to limit a physician's right to prescribe a medicinal product of his choice, naturally considering the diagnostic and therapeutic findings in a particular case, maintaining the legal and non-legal directives for physician's due diligence. This conclusion also applies to therapies with medicinal products used beyond registered indications" [23].

Although, the law neither excludes nor limits off-label use of drugs, the authors state that SPC provisions should not be 
subject to arbitrary and unlimited modification, especially in terms of non-adherence to registered indications incorporated in the SPC. It should be considered inherent to distinguish the primary meaning of off-label use, which should be understood as non-adherence to registered indications or the use of a product in an age group other than that indicated in the SPC, from its secondary meaning which should be identified as a change of dosage regimen, route of administration, or change of other conditions for drug use expressed in the SPC. As far as a change of route of administration or modification of dosage regimen can be justified by the individual specificity of a disease or a patients' individual traits, the use of drugs beyond registered indications should be justified by the need to save life or health. The authors' opinion correlates with the position of American oncologists; they emphasize that in cases when previously used medicinal products registered in oncological treatment do not have the expected outcome, the implementation of off-label treatment is admissible [24]. Moreover, as recent studies have shown, off-label use has not only a positive, but also a negative impact on the health of oncological patients [25]. The authors indicate the following, among others, indications for use of medicinal products beyond the SPC:

- direct threat to the life or health of a patient,

- exhaustion of the available and registered medicinal products and no expected outcome of therapy,

- the lack of medicinal products registered in a particular indication in the specified age group.

Automatic decision-making on the implementation of treatment beyond SPC without consideration. The point was to indicate analysing conditions given in a certain situation can represent the adoption of practice of drug use incompatible with the registration as a rule, as well as an increase of health risks associated with the use of drugs discordant with their formal registration. Admissibility of automatic use of off-label drugs emerges in a situation in which such possibility is foreseen by an announcement of the Minister of Health on the list of reimbursed medicines, foods for medical purposes and medical devices [26]. In specific cases, the refund announcement allows to prescribe a reimbursed medicine, even though the medicine is not registered in the indications concerned. Although it is the exception to the rule, according to which reimbursement corresponds with registered indications, the announcement does not refer to single use of off-label therapy. In the case when column no 13 of the appendix to the reimbursement announcement named "reimbursement indications beyond registration" includes specified units not included in the SPC, a drug can be prescribed with reimbursement in spite of not being registered in these indications [27]. The situation regarding off-label use of medicinal products based on drug programs is similar. Drug programs constitute the appendix to the reimbursement announcement which determines their binding nature. This means that a physician using a medicinal product beyond the SPC, in line with the drug program guideli- nes, is not subject to liability due to making such a decision and his activity is identified as exercising due diligence and fulfilling his obligations associated with the initiation of treatment of a patient qualified to the drug program [28].

\section{Off-label drug use and regulations for medical experiments}

Off-label use of medicinal products in its primary meaning should not be identified with a medical experiment in the true meaning of this concept. According to article 21 section 2 of the Act on the Profession of Doctor and Dentist [1]: "a medical experiment is the implementation of novel or only partially tested diagnostic, medical or prophylactic methods to achieve direct health benefit in a patient. It can be conducted if previously applied methods are not efficient or not sufficiently efficient (...)." The medical experiments category includes also research experiments. According to article 2 section 3 of the Act on the Profession of Doctor and Dentist [1] "a research experiment primarily aims at expanding medical knowledge (...)." Administration of an off-label drug does not have such an aim, however, in practice, it may enrich medical knowledge. Therefore, the use of drugs beyond the SPC in order to achieve optimal therapeutic effect cannot be in principle identified as a research experiment activity.

Regardless of whether a medical experiment is regarded as being of therapeutic or research in nature, eo ipso such activities contribute to the expansion of medical knowledge (especially evident in the case of research experiments). Administrating a particular patient an off-label drug does not have such an aim (although in practice it may enrich medical knowledge).

The fundamental difference between a medical experiment and the use of medicinal products beyond SPC, in the primary meaning, is the fact that activities of an experimental nature are entirely novel or only partially tested. On the other hand, the use of medicinal products discordant with registration indications is, in principle, an activity having its foundations in EBM, medical literature, and guidelines of teams of experts. Due to the safety of use specified by EBM, off-label drug use should be identified with regular medical service which is not a medically experimental. At the same time, it should be remembered that the regular health service, i.e. not experimental in nature, can be associated with an increased risk of a negative impact on a patient's life or health. The literature emphasizes that activity of an experimental nature cannot be identified with regular therapeutic activity [29]. What is more, the literature indicates that:"(...) only research activities conducted in line with generally accepted principles for scientific research, especially in strictly defined, purposefully chosen, precisely controlled conditions allowing for multiple replication, can be called medical experiment. Therefore unplanned, single use of a novel or unconventional treatment method applied by a physician to save a patient's life or health is not 
a medical experiment" [30]. In the authors'opinion, the medical experiment catalogue, within the meaning of provisions of chapter 4 of the Act on the Profession of Doctor and Dentist [1] (medical experiments) does not include single activities aiming at the protection of a patient's life or health in urgent cases, understood as all the cases in which the risk of loss of life, severe body injury or severe disorder of health occurs. As literal wording of article 30 of the Act on the Profession of Doctor and Dentist states: "a physician is obliged to provide medical aid in all cases when a delay in its provision could cause a risk of life loss, severe body injury or severe disorder of health" [1]. Therefore, the activities a physician is obliged to undertake in line with article 30 of the Act on the Profession of Doctor and Dentist [1] must not be identified with a medical experiment, which is due to the procedure of their implementation (urgent case), the nature of the activity (prophylactic, medical, and diagnostic activities), and the specifics of risk associated with refraining from the implementation of optimal methods of medical procedure (loss of life, severe disorder of health, severe body injury).

At the same time, urgent cases and measures should not be identified with an experiment carried out in conditions of an urgent cases and measures. In accordance with article 25a item 2 and 5 of the Act on the Profession of Doctor and Dentist [1], a medical experiment can be conducted without the participant's consent if the following conditions are met: "an urgent case occurs and due to the necessity to undertake immediate action, it is impossible to obtain consent for participation in the medical experiment from a legal representative of the participant or judicial authorization within a sufficiently short period of time", and "the experiment's participant [...] he and his legal representative will receive all significant information regarding participation in this experiment in the shortest period of time possible." However, it should be emphasized that all actions bearing the marks of a medical experiment in the understanding of the Act on the Profession of Doctor and Dentist can only be conducted after previously obtained positive opinion of the Bioethics Committee - article 29 section 1 of the Act on the Profession of Doctor and Dentist [1]. The above analysis clearly demonstrates that incidental medical activities aiming at saving life or health in urgent cases are not medical experiments, even if their nature is innovative, atypical or uncommon.

Assuming that the use of drugs beyond SPC is not of an experimental nature is crucial, among others, from the perspective of the obligation to conclude liability insurance by the entity conducting the experiment. According to article $23 \mathrm{c}$ section 1 of the Act on the Profession of Doctor and Dentist [1], the experimenting entity is obliged to conclude a separate liability insurance agreement covering the experiment's participant and a person who can be directly influenced by the effects of the experiment. Exception from the obligation to conclude liability insurance is defined in article 23 c section
2 of the Act on the Profession of Doctor and Dentist [1], stating that conducting a medical experiment in spite of lack of liability insurance is only admissible in the case of a need for the experiment in urgent mode or in the case when the life of the experiment's participant is threatened.

According to $\S 2$ of the Ordinance of the Minister of Finance, Funds and Regional Policy on compulsory civil liability insurance of the body carrying out the medical experiment [31], third party liability insurance is covered by the civil liability of the body carrying out the medical experiment for damage caused by its action or negligence to the participant and the person whose effects may be directly affected by the experiment, in connection with the medical experiment being carried out. As is indicated in the doctrine "both - the Pharmaceutical Law Act (article 37 b section 2 item 6) and the Act on Medical Devices (article 40 section 4 item 6) introduced a requirement to conclude mandatory liability insurance for damages caused due to conducting clinical trials. This resolution can be justified by the protection of participants' rights, for whom in case of a damage due to experimental activities, compensation would be guaranteed. However, application of these regulations is limited to research activities regulated pursuant to current acts. Therefore, it was demanded to unify these solutions and introduce them to chapter 4 of the Act on the Profession of Doctor and Dentist. Such a regulation was placed in the added article $23 \mathrm{c}$ which imposes such an obligation" (...) [32].

The use of medical products incompatible with SPC records does not constitute a medical experiment, if implementation of treatment aims at protecting the life or health of patients, instead of, for example, only observation of drug activity. In case of medical off-label use of medicinal products, provisions of the Act on the Profession of Doctor and Dentist on medical experiments have no appropriate application, therefore no obligation for concluding liability insurance by the entity which initiates and conducts such therapy occurs.

It should be emphasized that the use of medicinal products discordant with SPC represents exercising due diligence, provided that such activity constitutes optimal therapeutic management.

The issue of the lack of due diligence in treatment process was addressed by the Court of Appeal in Krakow in its judgement of 12.10.2007 [33], emphasizing that "it is a physician's fault not to exercise the highest degree of due diligence which is possible at currently used methods of treatment of a particular disease (...)." The use of medicinal products beyond SPC constitutes due diligence, provided that such activity is commonly accepted and applied, as well as being in line with the current state of medical knowledge.

According to P. Kwinta"continuous development in medical sciences (...) leads to the situation in which the information included in SPC, being a primary document required for drug 
registration, in some circumstances can be out-of-date" [34]. Both doctrine and judicature refer to the issues of the use of medicinal products discordant with registration provisions, however these issues are not treated in a uniform manner. Also, they are not directly regulated by the law.

\section{Obligation to provide information in case of off-label drug use}

In case of decision on off-label use of a drug a physician is obliged to inform a patient on possible results and complications of planned procedure, including alternative types of therapeutic management.

The obligation to provide information specified in article 31 section 1 of the Act on the Profession of Doctor and Dentist [1] requires that a physician provides, among others, information on the potential negative effects associated with a proposed treatment, the available alternative methods of proceeding, as well as the possible negative effects resulting from treatment initiation withdrawal. This issue becomes especially significant in cases where a physician proceeds discordant with SPC provisions, for the patient must know that such a method will be used and why a physician has decided to apply it. In the case where a patient accepts the offered nonstandard therapeutic management, they assume the risk associated with off-label drug administration. However, it is crucial to clarify the predictable consequences (favorable and unfavorable for the patient) of such a method of prescribing drugs [42-45]. The current case law states that once a patient is properly informed, he assumes the risk associated with the undertaken activities, under the condition that a "medical error", resulting in negative consequences, is not made by the physician $[46,47]$.

The literature emphasizes that the obligation to provide information is not limited to the level of information considered important by a physician, but a patient [35]. Due to the specificity and scope of results possibly occurring in treatment beyond the SPC, such activities should be identified as high-risk activities which highlights the importance of the obligation to provide information. In the authors' opinion, the risk of off-label treatment can be identified as typical (average) only in cases, when the use of a product incompatible with SPC is a common and schematic activity.

The doctrine emphasizes that"the lack of due diligence (provided for a professional) in the case of a physician, can involve the use of a drug in a defective way or to an inappropriate patient as well as the lack of possibility to predict adverse reactions of a drug as a result of a physician's insufficient knowledge regarding its properties or side effects when they possessed or should have possessed such knowledge. Responsibility for damage caused this way can be assigned to the physician (...), as lack of due diligence is a physician's fault. A physician (...) will be also responsible in case of prescribing or administering a patient drugs which harm the patient and the physician possessed or should have possessed knowledge on the properties of these drugs" [36]. In terms of the use of medicinal products beyond the SPC, prediction of all and even typical effects of their application is impossible due to the lack of previous drug assessment in terms of the risks associated with its use.

In view of the article 31 section 1 of the Act on the Profession of Doctor and Dentist, prior to off-label treatment initiation, a physician should deliver, among others, any information on effects and complications that may be predictable in light of the current medical knowledge, including these of casuistic occurrence. Case law indicates that an obligation to provide information covers normal, predictable, events even of rare occurrence, but impossible to exclude (...), especially those of a dangerous nature for life or health [37].

The delivery of understandable and comprehensive information on off-label treatment provides grounds for patient's informed consent for treatment [38]. In the judgement of 9.04.2019, the Court of Appeal in Warsaw itemed out that "the right for information - beside the right for consent - is in fact one of the most important elements of the relationship between the health care professional and the patient. Guaranteeing a patient the right to information is condition sine qua non of protection of his autonomy. Thereby the right for information should be treated as an instrument of significant importance (...)" [39]. On the other hand, the Court of Appeal in Warsaw, in the judgement of 19.02.2019, adopted a position that " $(. .$.$) obligation to provide appropriate information$ is in fact integrally associated with a physician's obligations concerning the treatment process alone. Properly fulfilled obligation to inform is a necessary condition for a patient's expression of legally binding consent (termed as "informed") for determined treatment; the ineffectiveness of consent due to the lack of delivery of appropriate information affirms the unlawful activities of a physician (...)" [40].

\section{Conclusions}

Polish law does not refer directly to the admissibility of off-label use of medicinal products, nor includes regulations forbidding to undertake such activities. The physician's obligation to exercise due diligence should be identified with, among others, the necessity to implement optimal pharmacological therapy in accordance with current medical knowledge. In some cases, optimal therapeutic management is associated with the necessary off-label use of medicinal products. However, the use of treatment beyond SPC provisions should not be the rule, but rather it should be justified by strictly defined conditions. The occurrence of conditions in the form of protection of health and life has particular relevance in a case when off-label products use consists of implementation or continuation of treatment with a product which was not registered in an indication in which it is used, or it is used in an age group not listed in the SPC. Off-label use of drugs should not be identified with an experiment in the understanding of the provisions of the Act on the Profession of Doctor and Dentist due to the 
different specificity of both activities, as well as the criteria to be met to undertake each activity.

Due to the nature of off-label therapy, its initiation or continuation requires particularly careful communication to the patient on the possible consequences of the action of the drug administered against the SPC provisions. Considering the number of problems associated with off-label use of drugs and, on the other hand, commonplace nature of such activities, the introduction of legal regulations defining the legitimacy and admissibility of such methods of proceeding is necessary. At the same time, it is necessary to initiate education of health professionals regarding the legal possibilities concerning off-label use of drugs, as well as prescribing beyond registration in line with the guidelines of reimbursement announcement.

\section{Conflict of interest: none declared}

\section{Janusz Jaroszyński \\ Maria Curie-Skłodowska University of Lublin \\ Faculty of Law and Administration \\ Department of Administrative Procedure \\ pl. Marii Curie-Skłodowskiej 5 \\ 20-031 Lublin, Poland \\ e-mail:janusz_jaroszynski@tlen.pl}

Received: 10 Aug 2021

Accepted: 11 Nov 2021

\section{References}

1. The Act on the Profession of Doctor and Dentist of 5.12.1996., ie. DzU 2021 r., pos. 719.

2. The Pharmaceutical Law of 06.09.2001, ie. DzU 2021 r., pos. 974, with changes.

3. Dal Pan GJ. Monitoring the safety of off label medicine use. WHO Drug Information 2009: 21-22.

4. Stafford RS. Regulating off-label drug use--rethinking the role of the FDA. N Engl J Med. 2008; 358(14): 1427-1429, doi: 10.1056/ NEJMp0802107, indexed in Pubmed: 18385495.

5. Directive 2001/83/EC of the European Parliament and of the Council of 6 November 2001 on the Community code relating to medicinal products for human use. OJ L 311/67. https://eur-lex.europa.eu/legal-content/PL/TXT/PDF/?uri=CELEX:32001L0083\&from=EN (01.08.2021).

6. https://rejestrymedyczne.ezdrowie.gov.pl/rpl/search/public (01.08.2021)

7. MatusewiczW. Stosowanie leków w onkologii i hematologii w zakresie wskazań do stosowania lub dawkowania, lub sposobu podawania odmiennych niż określone w Charakterystyce Produktu Leczniczego, Warszawa 2012. http://www.korektorzdrowia.pl/wp-content/uploads/ prezes-aotm-wojciech-matusewicz-stosowanie-lekow.pdf (01.08.2021).

8. Saiyed MM, Ong PS, Chew L. Off-label drug use in oncology: a systematic review of literature. J Clin Pharm Ther. 2017; 42(3): 251-258, doi: 10.1111/jcpt.12507, indexed in Pubmed: 28164359.

9. Herbrand AK, Schmitt AM, Briel M, et al. Association of Supporting Trial Evidence and Reimbursement for Off-Label Use of Cancer Drugs. JAMA Netw Open. 2021; 4(3): e210380, doi: 10.1001/jamanetworkopen.2021.0380, indexed in Pubmed: 33651108.

10. Bun S, Yonemori K, Sunadoi H, et al. Safety and Evidence of Off-Label Use of Approved Drugs at the National Cancer Center Hospital in Japan. JCO Oncol Pract. 2021; 17(3): e416-e425, doi: 10.1200/OP.20.00131, indexed in Pubmed: 32956004.

11. Poole SG, Dooley MJ. Off-label prescribing in oncology. Support Care Cancer. 2004; 12(5): 302-305, doi: 10.1007/s00520-004-0593-6, indexed in Pubmed: 14986075.
12. Rückeshäuser P. Off label use: the legal problems of drug application beyond the licensed use. , Hamburg 2011: 1-386.

13. Emmerich J, Dumarcet N, Lorence A. France's new framework for regulating off-label drug use. N Engl J Med. 2012; 367(14): 1279-1281, doi: 10.1056/NEJMp1208347, indexed in Pubmed: 23034018.

14. Choonara I, Conroy S. Unlicensed and off-label drug use in children: implications for safety. Drug Saf. 2002; 25(1): 1-5, doi: 10.2165/00002018200225010-00001, indexed in Pubmed: 11820908.

15. Masełbas W, Członkowski A. Stosowanie produktów leczniczych poza wskazaniami rejestracyjnymi. Przewodnik Lekarza. 2008; 3: 81-87.

16. Vrancken I. Off-label Prescription of Medication. European Journal of Health Law. 2015; 22(2): 165-186.

17. Radley DC, Finkelstein SN, Stafford RS. Off-label prescribing among office-based physicians. Archives of Internal Medicine. 2006; 9: 1021-1026.

18. Kapko M. In: Zielińska E. ed. Ustawa o zawodach lekarza i lekarza dentysty. Comment. Wolters Kluwer Polska 2008: 528.

19. The Judgment of the Court of Appeal in Warsaw of 14.02.2014, no, VI ACa 1000/13, LEX nr 1469448.

20. The Judgment of the Supreme Court of 24.11.2011, no, I CSK 69/11, OSNC 2012/5/63 2012.

21. The Resolution of the Supreme Court of 26.10.2011, no, III CZP 58/11, OSNC 2012/5, pos. 59.

22. WidłakT. nterpretacja klauzuli „,aktualna wiedza medyczna” w polskim prawie - zarys zagadnień epistemologicznych i metodologicznych. Gdańskie Studia Prawnicze. 2017; 38.

23. Luty O. Zaniechanie zlecenia produktu leczniczego poza zarejestrowanym wskazaniem a odpowiedzialność cywilna lekarza. PiM. 2014; 2: 132-150.

24. American Society of Clinical Oncology. Reimbursement for cancer treatment: coverage of off-label drug indications. J Clin Oncol. 2006; 24(19): 3206-3208, doi: 10.1200/JCO.2006.06.8940, indexed in Pubmed: 16717290.

25. Lim M, Shulman DS, Roberts $\mathrm{H}$, et al. Off-label prescribing of targeted anticancer therapy at a large pediatric cancer center. Cancer Med. 2020; 9(18): 6658-6666, doi: 10.1002/cam4.3349, indexed in Pubmed: 32750219.

26. The Announcement of the Minister of Health of 21.06.2021, on the list of reimbursed medicines, foods for special medical purposes and medical devices as of 1st July 2021. https://www.gov.pl/web/zdrowie/ obwieszczenia-ministra-zdrowia-lista-lekow-refundowanych.

27. Chromiec Z, Hoffmann E. Stosowanie leków poza wskazaniami przesłanki oraz refundacja. Folia Cardiologica. 2020; 15(2): 188-191, doi: $10.5603 / f c .2020 .0024$.

28. Zajdel. Dopuszczalność stosowania produktów leczniczych poza ChPL w programie lekowym "Leczenie przetoczeniami immunoglobulin w chorobach neurologicznych". Neuroedu.pl. file:///C:/Users/User/Downloads/neuroedu\%202016\%20Dopuszczalno\%C5\%9B\%C4\%87\%20 stosowania.pdf (01.08.2021).

29. Safjan M. Prawo i medycyna. Ochrona praw jednostki a dylematy współczesnej medycyny. , Warszawa 1998: 172

30. Kondrat M. (ed.). Prawo farmaceutyczne. Komentarz, ed. II. WKP 2016.

31. The Regulation of the Minister of Finance, Development Funds and Regional Policy on mandatory liability insurance of the entity conducting medical experiment, DzU 2020, pos. 2412.

32. Kubiak R. Nowe uwarunkowania prawne przeprowadzania eksperymentów medycznych. PS. 2021; 1: 5-26.

33. The Judgment of the Court of Appeal in Kraków of 12.10.2007, no., I ACa 920/07, LEX no 570272.

34. Kwinta P. Stosowanie leków poza rejestracją u dzieci - perspektywa lekarza. Przeglad Lekarski. 2011;68: 1-3.

35. Aagaard L, Kristensen K. Off-label and Unlicensed Prescribing in Europe: Implications for Patients'Informed Consent and Liability. International Journal of Clinical Pharmacy. 2018; 40(3): 509-512.

36. Gęsicka DK. Odpowiedzialność za szkody wyrządzone przez produkty lecznicze - zagadnienia wybrane. Prawo i Medycyna. 2013(3-4): 189-208.

37. The Judgment of the Supreme Court of 18.01 .2013 , no, IV CSK 431/12, Lex no 1275006.

38. Zajdel J. Prawo medyczne. PZWL, Warszawa 2019.

39. The Judgment of the Court of Appeal in Warsaw of 9.04.2019, no, akt V ACa 147/18, Lex no 2668829.

40. The Judgment of the Court of Appeal in Warsaw of 19.02.2019, no, V ACa 119/18, Lex no 2631471.

41. The Civil Code of 23.04.1964, ie. DzU 2020, pos. 1740.

42. Kubiak R. Prawo medyczne. C.H.Beck, Warszawa 2017: 291-295. 
43. The Judgment of the Supreme Court of 28.08.1972, no akt II CR 296/72, OSNC, No 5/1973, pos. 86

44. The Judgment of the Court of Appeal in Kraków of 06.09.2012 r., no akt I ACa 723/12, LEX no 1236722.

45. The Judgment of the Supreme Court of 28.09.1999 r., no akt II CKN 511/96, LEX no 453701).
46. The Judgment of the Court of Appeal in Szczecin of 11.05.2017, no akt I Aca 560/15, LEX no 2376937.

47. The Judgement of the Court of Appeal in Katowice of 18.01.2017 r., no akt V ACa 146/16, LEX no 2233014. 